\title{
Short communication: Effect of homogenization on heat inactivation of Mycobacterium avium subspecies paratuberculosis in milk
}

\author{
P. Hammer, ${ }^{1}$ C. Kiesner, and H.-G. C. Walte \\ Department of Safety and Quality of Milk and Fish Products, Max Rubner-Institute, Federal Research Institute of Nutrition and Food, 24103 Kiel, \\ Germany
}

\begin{abstract}
Mycobacterium avium ssp. paratuberculosis (MAP) can be present in cow milk and low numbers may survive high-temperature, short-time (HTST) pasteurization. Although HTST treatment leads to inactivation of at least $5 \log _{10}$ cycles, it might become necessary to enhance the efficacy of HTST by additional treatments such as homogenization if the debate about the role of MAP in Crohn's disease of humans concludes that MAP is a zoonotic agent. This study aimed to determine whether disrupting the clumps of MAP in milk by homogenization during the heat treatment process would enhance the inactivation of MAP. We used HTST pasteurization in a continuous-flow pilotplant pasteurizer and evaluated the effect of upstream, downstream, and in-hold homogenization on inactivation of MAP. Reduction of MAP at $72^{\circ} \mathrm{C}$ with a holding time of $28 \mathrm{~s}$ was between 3.7 and $6.9 \log _{10}$ cycles, with an overall mean of $5.5 \log _{10}$ cycles. None of the 3 homogenization modes applied showed a statistically significant additional effect on the inactivation of MAP during HTST treatment.
\end{abstract}

Key words: Mycobacterium paratuberculosis, milk, homogenization, heat inactivation

\section{Short Communication}

It is widely known that Mycobacterium avium ssp. paratuberculosis (MAP) can be present in cow milk and that low numbers may survive HTST pasteurization $\left(15 \mathrm{~s}\right.$ at $\left.72^{\circ} \mathrm{C}\right)$. This is reflected in findings of several studies that report the presence of viable MAP in HTST-treated milk at the retail level (Grant et al., 2002a; Ayele et al., 2005; Ellingson et al., 2005; Shankar et al., 2010). Although HTST pasteurization leads to inactivation of $5 \log _{10}$ cycles or more, it might become necessary to enhance the efficacy of HTST by additional treatments such as homogenization, bactofu-

Received August 12, 2013.

Accepted December 10, 2013.

${ }^{1}$ Corresponding author: philipp.hammer@mri.bund.de gation, or microfiltration. This would be the case if the debate about the role of MAP in Crohn's disease of humans concludes that MAP is a zoonotic agent.

The basis of this study was that MAP in culture, as well as in feces, occurs in clumps of up to several thousand cells. Although the time needed for heat penetration of bacterial clumps is estimated to be in the range of few hundredths of a second (Davey, 1990), some evidence indicates that breaking up clumps by homogenization during the heat treatment process of milk might enhance the inactivation of MAP (Grant et al., 2005). To further investigate this, we applied HTST pasteurization in a continuous-flow pilot-plant pasteurizer in combination with upstream, downstream, and in-hold homogenization with an aseptic homogenizer.

Three MAP strains were used in our experiments: ATCC 19851, Niebuell (from our own strain collection, and isolated from an aseptically drawn milk sample of a clinically diseased cow), and NIZO 2962 (isolated from feces of a clinically diseased cow, kindly provided by Jan Rademaker, NIZO Food Research, Ede, the Netherlands).

We applied an in-house method for culture detection of heat-injured MAP; the method has been used for several years and includes resuscitation and incubation times up to 1 yr (Hammer et al., 2002). Milk samples were collected from the outlet of the pasteurizer. For each experiment, $300 \mathrm{~mL}$ was collected and split into 2 sub-samples of $150 \mathrm{~mL}$ each, which were processed independently. Splitting the sample has the advantage that, if there are surviving bacteria other than MAP, at least some of the subsequent cultures are not contaminated. This proved useful during the detection and isolation of the agent because no decontamination procedure of the heat-treated samples was done to avoid decreasing the viability of the surviving mycobacteria. The sample temperature at collection was $<12^{\circ} \mathrm{C}$ and further cooling was not applied. Directly after collection (maximum of 1-h delay), samples were processed as described in Hammer et al. (2013).

A detailed description of the pilot-plant pasteurizer and its operation is given in Hammer et al. (2002), and a brief description is given in Peng et al. (2013). The ho- 
Table 1. Inactivation of Mycobacterium avium ssp. paratuberculosis (MAP; results for 3 MAP strains combined) in milk during upstream, downstream, and in-hold homogenization in combination with HTST treatment (holding time 27-28 s)

\begin{tabular}{|c|c|c|c|c|c|c|c|c|}
\hline Mode & \multicolumn{4}{|c|}{ With homogenization } & \multicolumn{4}{|c|}{ Without homogenization } \\
\hline Upstream & $8 / 9$ & $4.0-6.9$ & $8 / 9$ & $4.0-6.9$ & $6 / 9$ & $4.0-6.8$ & $7 / 9$ & $4.0-6.8$ \\
\hline Downstream & $9 / 9$ & $3.7-6.6$ & $8 / 9$ & $3.7-6.1$ & $9 / 9$ & $3.7-6.2$ & $7 / 9$ & $3.7-6.2$ \\
\hline
\end{tabular}

${ }^{1}$ For means, see Table 2 .

mogenizer used for the experiments was a commercial, small-scale unit (model LAB 60-10 TBSX; APV Gaulin BV, Hilversum, the Netherlands). For upstream and downstream homogenization, the homogenizer was connected to cans for feeding and sampling. For upstream homogenization, the feeding can contained untreated raw milk. After homogenization, the sampling can was connected to the pilot plant for further HTST treatment. For downstream homogenization, the milk first was HTST treated and sampled in the feeding can of the homogenizer. Subsequently, this can was connected to the homogenizer and homogenization took place. For in-hold homogenization, the homogenizer was placed in-line, replacing the holding section. The plunges were surrounded by a steam chest, which was filled with floating steam during operation. During up- and downstream operation, the same sample cans as used for the pilot plant were connected and the respective contents continuously stirred. The time delay between treatments with the pilot plant and the homogenizer, due to connection and disconnection of the sample cans, was less than $10 \mathrm{~min}$. After cleaning, the homogenizer was sterilized by application of floating steam for 10 min. Basic technical data were as follows: flow rate was fixed at $50 \mathrm{~L} / \mathrm{h}$; pressure was variable between 0 and 70 $\mathrm{MPa}$, with accuracy of $\pm 1 \mathrm{MPa}$; and pressure applied was $20 \mathrm{MPa}$ (which reflects the situation in practice).

For in-hold homogenization, where the homogenizer was run in-line in the pasteurizer, the speed of the product pump of the pasteurizer and of the homogenization pump had to be harmonized, which resulted in a fixed flow rate of $50 \mathrm{~L} / \mathrm{h}$. This resulted in a holding time of $27.8 \mathrm{~s}$, on average. As this holding time was not variable, the same holding time was used also for HTST with upstream and downstream homogenization to maintain comparability.

For the MAP strains ATCC 19851, Niebuell, and NIZO 2962, upstream, in-hold, and downstream homogenization in combination with HTST was tested at 72 and $68^{\circ} \mathrm{C}$, with a holding time of approximately $28 \mathrm{~s}$. Each experiment was performed in triplicate. Raw milk from our own experimental herd (free from paratuberculosis) inoculated with MAP was used.

For inoculation of raw milk, each MAP strain was grown for 8 to $10 \mathrm{wk}$ in $2 \times 1 \mathrm{~L}$ of modified Dubos medium. Bacteria were harvested from the growth

Table 2. Statistical analysis of the influence of different homogenization modes on the inactivation of Mycobacterium avium ssp. paratuberculosis (MAP) in milk; reduction values are given in $\log _{10}$ cycles $^{1}$

\begin{tabular}{llcccc}
\hline Mode 1 & Mode 2 & LSM 1 & LSM 2 & Difference & $P$-value \\
\hline At $68^{\circ} \mathrm{C}$ & & & & \\
Without & In-hold & 5.65 & 4.42 & 1.23 & $<0.05$ \\
Without & Upstream & 5.65 & 5.50 & 0.15 & NS \\
Without & Downstream & 5.65 & 5.59 & 0.06 & NS \\
In-hold & Upstream & 4.42 & 5.50 & -1.08 & $<0.01$ \\
In-hold & Downstream & 4.42 & 5.59 & -1.17 & $<0.01$ \\
Upstream & Downstream & 5.50 & 5.59 & -0.09 & NS \\
At 72 C & In-hold & 5.58 & 5.82 & -0.24 & NS \\
Without & Upstream & 5.58 & 5.50 & 0.08 & NS \\
Without & Downstream & 5.58 & 5.59 & -0.01 & NS \\
Without & Upstream & 5.82 & 5.50 & 0.32 & NS \\
In-hold & Downstream & 5.82 & 5.59 & 0.23 & NS \\
In-hold & Downstream & 5.50 & 5.59 & -0.09 & NS \\
Upstream & . & & &
\end{tabular}

${ }^{1}$ Homogenization modes upstream, downstream, in-hold, and without homogenization were compared as listed under mode 1 and 2; LSM 1 and 2 indicate least squares means for modes 1 and 2, respectively. 
medium by centrifugation for $15 \mathrm{~min}$ at $2,200 \times g$; pellets were resuspended in $0.85 \% \mathrm{NaCl}$ by gentle shaking and were not homogenized before further use. This procedure results in a cell suspension containing single cells and cells in clumps of different sizes, similar to those found in the fecal matter of infected cows. Thirty liters of raw milk was directly inoculated with the resuspended strains and stirred continuously with a magnetic stirrer in the respective tank of the pilot plant during the heating run. Colony counts before heating were determined by direct plating onto Herrold's egg yolk medium. Inocula achieved were between $10^{2}$ and $10^{5} \mathrm{cfu} / \mathrm{mL}$ of raw milk.

For statistical evaluation, an analysis of covariance was performed. Calculation was carried out with the GLM (general linear model) procedure in SAS (version 9.2; SAS Institute Inc., Cary, NC), including additive constants to an overall mean and considering at the same time a regression relationship to a covariate. The following factors were included: strain, temperature, mode (homogenization upstream, in-hold, or downstream), and as covariate the initial bacterial count $(\mathrm{cfu} / \mathrm{mL})$. Only the interaction mode $\times$ temperature was included, because no other combination was significant. Linear contrasts were used to analyze the differences between the least squares means (LSM) estimates.

Values for log reduction were determined from direct colony counts on Herrold's egg yolk medium or from positive results after enrichment in modified Dubos medium. If neither of these showed a result, the initial MAP count was used as an estimate for the minimum reduction achieved, although the actual reduction could have been higher (Table 1). Because no significant difference was found in survival of the 3 test strains, results for these were combined. For statistical analysis, data on log reductions were compared in a general linear model. Only the interaction homogenization mode $\times$ temperature showed was significant; bacterial strain and initial count had no influence (Table 2). At a heating temperature of $68^{\circ} \mathrm{C}$, upstream and downstream homogenization had the same efficacy as the mode without homogenization, and in-hold homogenization was even less effective than the other 2 modes. At $72^{\circ} \mathrm{C}$, no significant effects of homogenization were detected. Regarding the reduction of MAP by HTST treatment in general, our previous findings and those of others were confirmed (Pearce et al., 2001; Grant et al., 2002b; Hammer et al., 2002; McDonald et al., 2005). Reduction at $72^{\circ} \mathrm{C}$ was at least 3.7 and reached $6.9 \log _{10}$ cycles, the overall mean being $5.5 \log _{10}$ cycles.

The presence and size of clumps was not determined before or after homogenization. Milk was spiked with MAP without measures for declumping because the bacteria also occur in clumps in feces (the main contamination source for milk). Homogenization was performed at $20 \mathrm{MPa}$, which corresponds to the standard used in practice. The size of fat droplets after homogenization at this pressure is expected to be between 0.4 and $<1 \mu \mathrm{m}$, which is close to the longitudinal size of MAP, so breaking up of clumps is likely to occur at this pressure. Time for heat penetration of a bacterial clump is estimated to be 0.02 to $0.03 \mathrm{~s}$ (Davey, 1990). This means that it does not matter whether MAP (and other bacteria) occur in clumps or not during heating, which corresponds with our results. If the efficacy of homogenization depends on reduction of clump size or by shear force, then the downstream mode should have no effect, whereas the upstream and in-hold modes should have an effect. The results clearly show, however, that homogenization did not have any effect, regardless of mode.

High-temperature, short-time pasteurization at $72^{\circ} \mathrm{C}$ for 27 to 28 s reduced MAP numbers by up to $6.9 \log _{10}$ cycles; however, none of the 3 homogenization modes (upstream, in-hold, or downstream) increased the efficacy over that achieved by HTST alone.

\section{ACKNOWLEDGMENTS}

The authors thank Susanne Cochoy (Max RubnerInstitute, Department of Safety and Quality of Milk and Fish Products, Kiel, Germany) for excellent technical assistance in the heating experiments, and Guenther Schubert (Max Rubner-Institute) for building the pilot plant and modifying the homogenizer. In addition, the authors acknowledge the financial support of the European Community (EU-project ParaTBTools contract FP6-FOOD-CT-2006-023106).

\section{REFERENCES}

Ayele, W. Y., P. Svastova, P. Roubal, M. Bartos, and I. Pavlik. 2005. Mycobacterium avium ssp. paratuberculosis cultured from locally and commercially pasteurized cow's milk in the Czech Republic. 2005. Appl. Environ. Microbiol. 71:1210-1214.

Davey, K. R. 1990. Equilibrium temperature in a clump of bacteria heated in fluid. Appl. Environ. Microbiol. 56:566-568.

Ellingson, J. L. E., J. L. Anderson, J. J. Koziczkowsk, R. P. Radcliff, S. J. Sloan, S. E. Allen, and N. M. Sullivan. 2005. Detection of viable Mycobacterium avium ssp. paratuberculosis in retail pasteurized whole milk by two culture methods and PCR. J. Food Prot. 68:966-972.

Grant, I. R., H. J. Ball, and M. T. Rowe. 2002a. Incidence of Mycobacterium paratuberculosis in bulk raw and commercially pasteurized cow's milk from approved dairy processing establishments in the United Kingdom. Appl. Environ. Microbiol. 68:2428-2435.

Grant, I. R., E. I. Hitchings, A. McCartney, F. Ferguson, and M. T. Rowe. 2002b. Effect of commercial-scale high-temperature, shorttime pasteurisation on the viability of Mycobacterium paratuberculosis in naturally infected cow's milk. Appl. Environ. Microbiol. 68:602-607.

Grant, I. R., A. G. Williams, M. T. Rowe, and D. D. Muir. 2005. Efficacy of various pasteurization time-temperature conditions in 
combination with homogenization on inactivation of Mycobacterium avium ssp. paratuberculosis in milk. Appl. Environ. Microbiol. 71:2853-2861.

Hammer, P., C. Kiesner, H.-G. Walte, K. Knappstein, and P. Teufel. 2002. Heat resistance of Mycobacterium avium ssp. paratuberculosis in raw milk tested in a pilot plant pasteurizer. Kieler Milchwirtsch. Forschungs. 54:275-303.

Hammer, P., H.-G. C. Walte, S. Matzen, J. Hensel, and C. Kiesner. 2013. Inactivation of Mycobacterium avium ssp. paratuberculosis during cooking of hamburger patties. J. Food Prot. 76:1194-1201.

McDonald, W. L., K. J. O'Riley, C. J. Schroen, and R. J. Condron. 2005. Heat inactivation of Mycobacterium avium ssp. paratuberculosis in milk. Appl. Environ. Microbiol. 71:1785-1789.

Pearce, L. E., H. T. Truong, R. A. Crawford, G. F. Yates, S. Cavaignac, and G. W. de Lisle. 2001. Effect of turbulent-flow pasteuri- sation on survival of Mycobacterium avium ssp. paratuberculosis added to raw milk. Appl. Environ. Microbiol. 67:3964-3969.

Peng, S., J. Hummerjohann, R. Stephan, and P. Hammer. 2013. Short communication: Heat resistance of Escherichia coli strains in raw milk at different subpasteurization conditions. J. Dairy Sci. 96:3543-3546.

Shankar, H., S. V. Singh, P. K. Singh, A. V. Singh, J. S. Sohal, and R. J. Greenstein. 2010. Presence, characterization, and genotype profiles of Mycobacterium avium ssp. paratuberculosis from unpasteurized individual and pooled milk, commercial pasteurized milk, and milk products in India by culture, PCR, and PCR-REA methods. Int. J. Infect. Dis. 14:e121-e126. 